\title{
OVERVIEW OF HISTORICAL AND FUTURE TRENDS OF COMMERCIAL AIRCRAFT FUEL EFFICIENCY
}

\author{
Jarosław KOZUBA \\ Silesian University of Technology, Faculty of Transport, Akademicka 2A, 44-100 Gliwice, Poland \\ Mateusz OJCIEC \\ Technical University of Košice, Faculty of Aeronautics, Rampova 7, 04121 Košice, Slovakia \\ *Corresponding author. E-mail: mateusz.ojciec92@gmail.com
}

\begin{abstract}
The common factor for all airlines in reducing aircraft operating costs is improving fuel economy. Many international organizations such as EASA, ICAO or ICCT as well as aircraft operators put strong emphasis on improving aircraft fuel efficiency not only for economical but also for ecological reasons. It can be noticed that biggest improvements are achieved through implementation of new aircraft models and engines. Fuel consumption goals have been set by ICAO to achieve an annual improvement of $2 \%$ from year 2020 to 2050, however according to some experts this goal is probably is not going to be met as industry is lagging approximately 12 years behind this plan due to technological and economic reasons.
\end{abstract}

Keywords: fuel economy; optimization; aircraft engines; efficiency

\section{INTRODUCTION}

Currently presented fuel efficiency rankings of commercial aircraft very often do not include piston aircraft coming from the pre-jet era. An example of such ranking can be the often-cited IPCC Special Report on Aviation and the Global Atmosphere. Based on micro and macro analyses it is possible to conclude that the late piston-powered aircraft were as fuel efficient as the current average jet and twice as efficient as the first jet airplanes which directly replaced them [1]. While this statement is true, in the modern era the number of piston aircraft used in commercial operations is so low that this data has no significant impact on the global research. Therefore this research puts strong emphasis on jet aircraft.

Due to large competition and dynamically changing market airlines are forced to put heavy emphasis on lowering expenses throughout their whole operation span. These goals have to be achieved while taking safety as the most important factor in any airline operation. Methods of lowering operating costs can strongly vary between airlines depending on their economics, type of operations, maintenance management or technical condition of their fleets [2].

Nowadays the fuel costs can make up to $43 \%$ of aircraft operating costs [3]. This is a noticeable increase over the past few years. Combined with the constantly growing number of aircraft operations, as well as the relatively high jet fuel prices, costs of operating an aircraft start growing. [4]. This article is aimed to present a review of how aircraft fuel economy has changed over time and what are the future trends for further improvements in this field. Research has been based on multiple sources such as analyses provided by international organizations, e.g. EASA and ICAO, as well as independent expert opinions and airline sustainability reports. 


\section{ANALYSIS OF HISTORICAL AND CURRENT TRENDS IN AIRCRAFT FUEL ECONOMY}

Lowering fuel consumption of aircraft engines is necessary from both economic and ecological reasons. Because of that it can be often noticed that aircraft fuel efficiency is measured not only based on amount of fuel used but also includes emissions of exhaust gasses into atmosphere.

An example of such approach can be found in the highly respected reports of the International Council on Clean Transportation. In their latest report published in 2015 Council used the analysis of fuel efficiency trends under the ICAO (International Civil Aviation Organization) $\mathrm{CO}_{2}$ standard metric value (MV) instead of traditionally used fuel/tonne-kilometer metric. Average fuel burn trend presented in figure 1 has been calculated under the following conditions and assumptions for better accuracy:

- $\quad$ nine test points (combinations of three payloads and three range test points) were used for each aircraft type;

- $\quad$ aircraft seating density has been standardized by type [5].

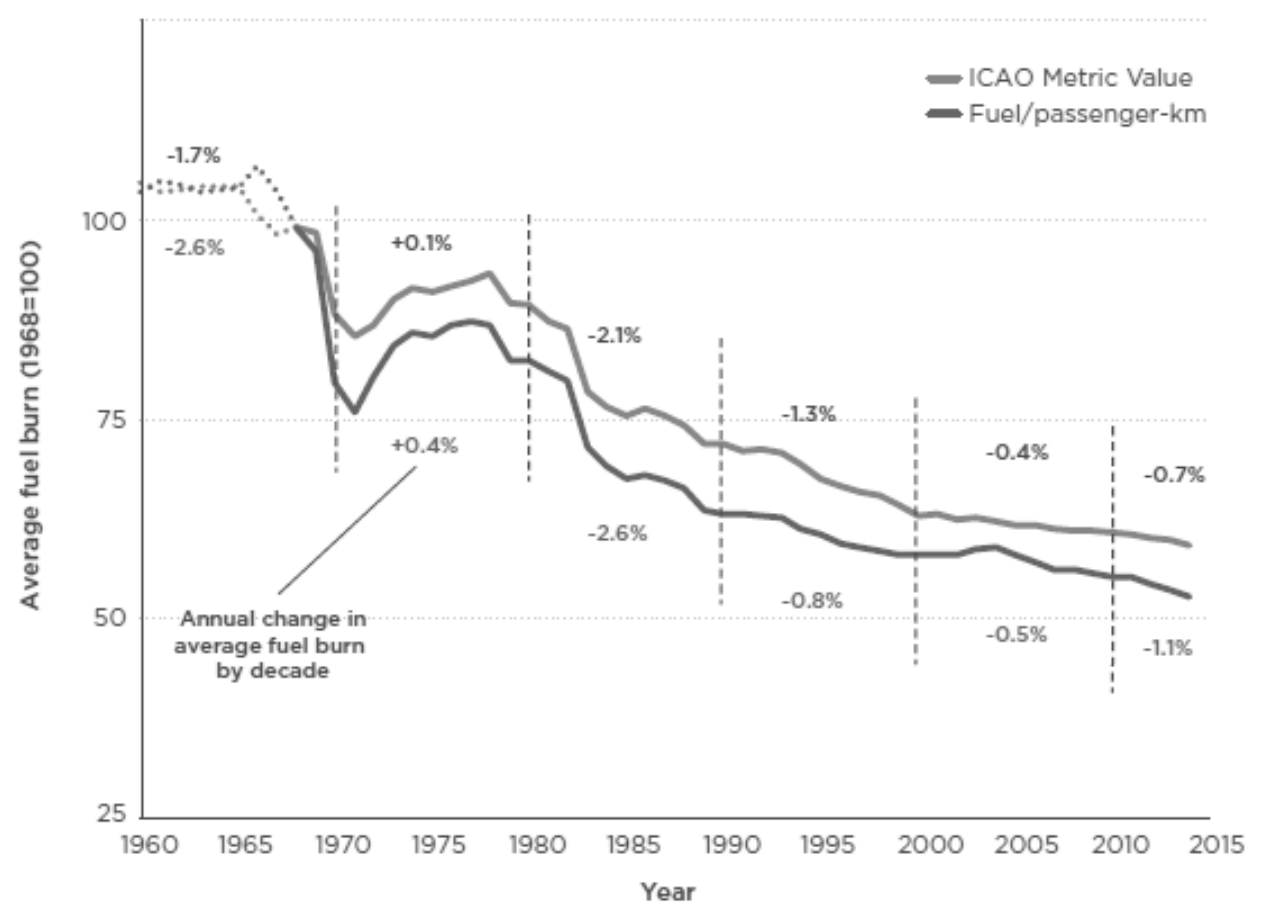

Figure 1 Average fuel burn for new commercial jet aircraft in the years 1960-2015 [5]

It is possible to determine that a constant significant improvement has occurred in the period between years 1980 and 1990. This has been most probably caused by popularization and big advances of high-bypass turbofan engines. Also, in this time period the Boeing 737 Classic and Airbus A320 aircraft were created. As these models became very popular within airlines around the world they have made a significant impact on presented statistic.

A different data set presenting aircraft fuel consumption and emissions has been created by EASA in their European Aviation Environmental Report 2019. 


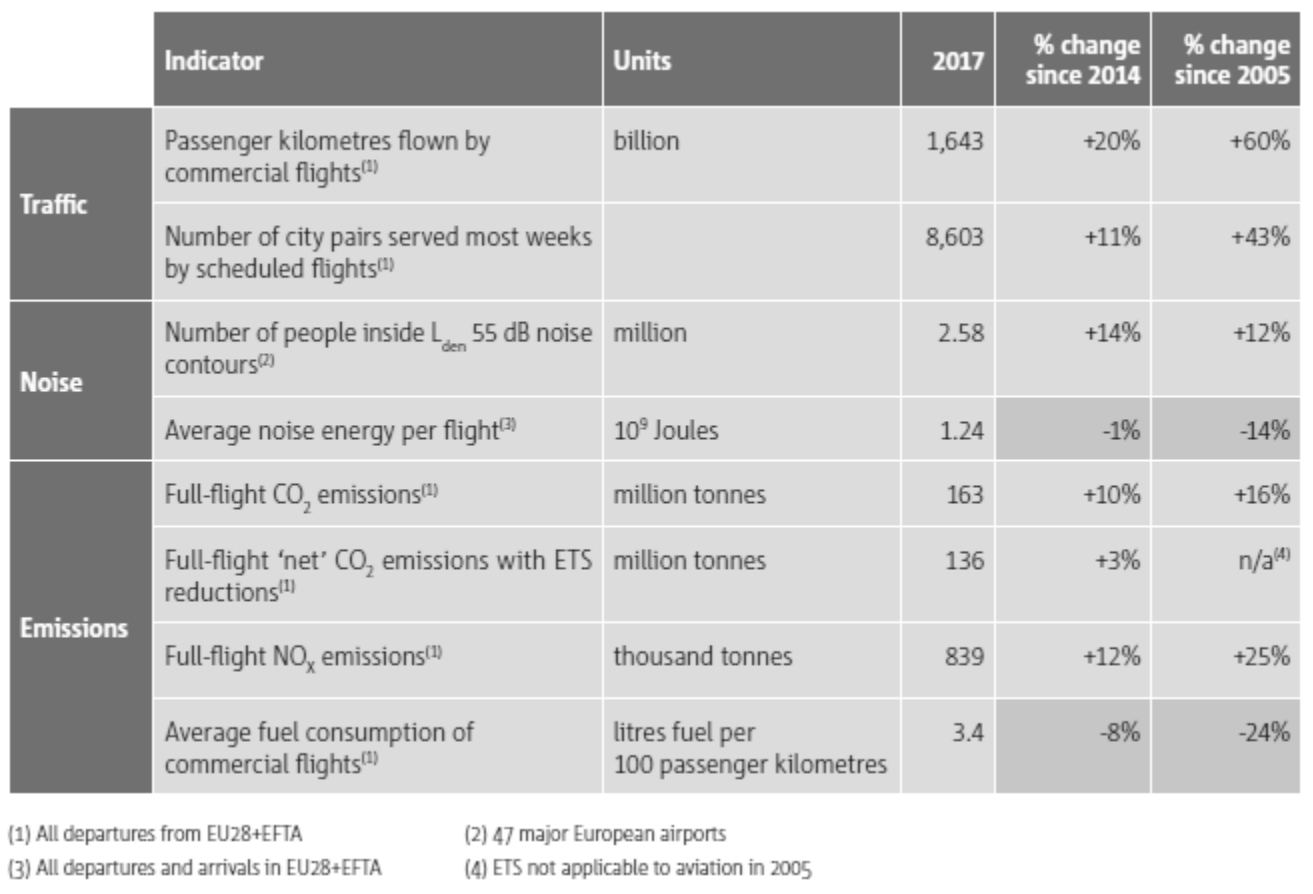

Figure 2 Changes in aircraft traffic, noise and emission in the years 2005-2017 [6]

It can be noticed that the average fuel consumption of commercial flights has decreased by $24 \%$ since 2005 and by $8 \%$ since 2014. It is a large difference, however it does not make a major impact on global data presented in figure 1. At the same time, it is important to keep in mind that this statistic has been created based only on EU and EFTA countries. The most probable reason for that is that old airplanes which are no longer used in EU are not scrapped, but rather sold to airlines operating in different regions.

Nowadays more and more airlines put high emphasis on fuel efficiency of their aircraft. Apart from bringing financial benefits such approach is often used also for marketing purposes. Airlines such as Norwegian, Finnair or now defunct Wow Air often show their passengers that they are 'greener' than their competitors. Norwegian in their sustainability report published in 2017 says: 'Norwegian is committed to actively engage in and support a sustainable environmental policy and believes that, until there is a greener alternative that is commercially available, the single most important action an airline can take to reduce its environmental footprint is to invest in new aircraft, which reduces fuel burn and hence emissions considerably.'. This strategy has led Norwegian to become industry leader in terms of fuel efficiency [7].

It is worth noticing that all of the airlines being on top of this ranking have relatively young fleets. The average age of Boeing 787 aircraft operated by Norwegian on transatlantic routes is 3,3 years, while Swiss airlines fleet of Airbus A330s and Boeing 777s has an average age of 5,4 years. For comparison average age of long haul airplanes operated by British Airways (Airbus A380, Boeing 747, Boeing 777, Boeing 787) is 13,6 years. For Lufthansa the average age of their fleet of Airbus A330s, A340s, A350s, A380s, Boeing 747s and Boeing 777s is 10,4 years. 


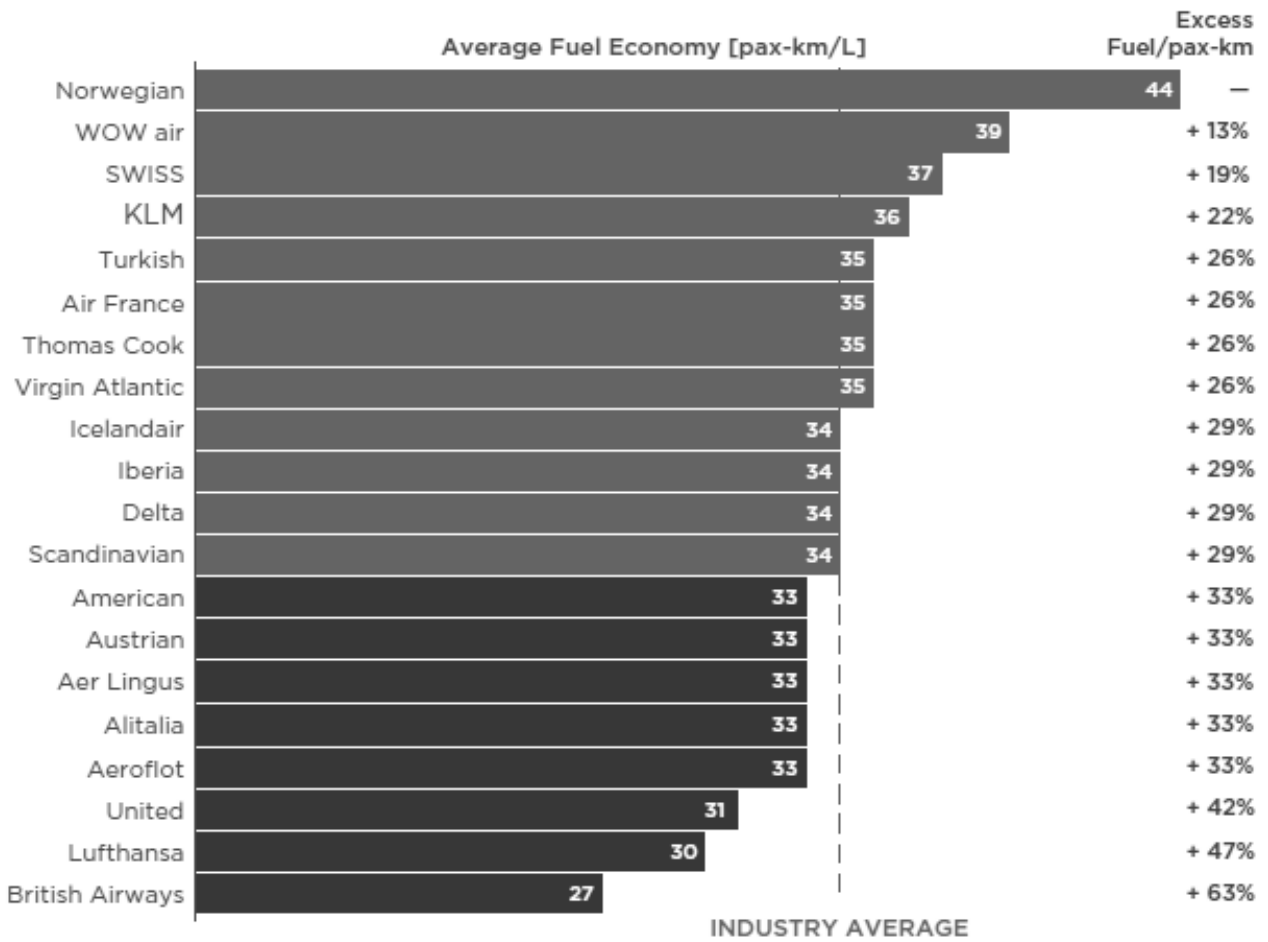

Figure 3 Fuel efficiency of 20 airlines on transatlantic passenger routes, 2017 [8]

\section{POSSIBILITIES FOR IMPROVEMENTS IN FUEL ECONOMY IN THE FUTURE}

In 2016 ICAO has published an Environmental Report titled On Board - A Sustainable Future. In this report a goal was set to improve fuel efficiency by $2 \%$ on annual basis and to ser carbon neutral growth. This goal should be achieved by implementation of innovative aircraft technologies, more efficient operations, sustainable alternative fuels and market-based measures. Figure 3 presents the anticipated future trend of improvement in fuel burn efficiency up to year 2040 with interpolation up to year 2050 [9].

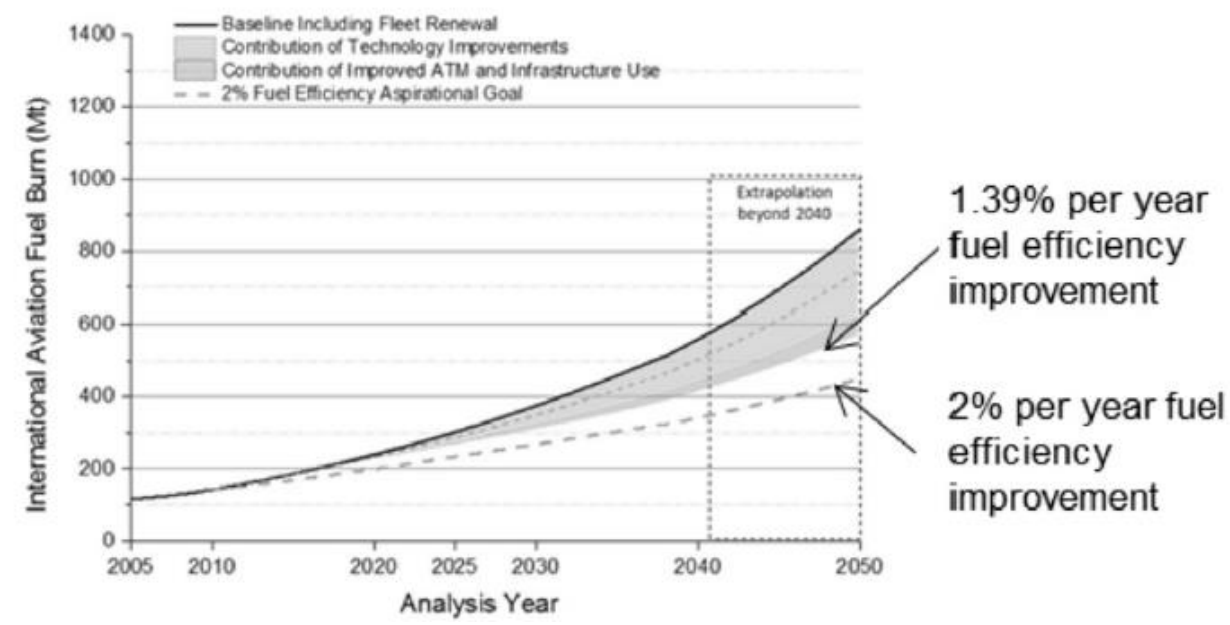

Figure 4 Fuel burn trends for international aviation in years 2005-2050 [9]

While these goals are very ambitious and needed, some experts believe that they are not achievable. Authors of the International Council on Clean Transportation have come to a conclusion that goals set by ICAO cannot be reached. 


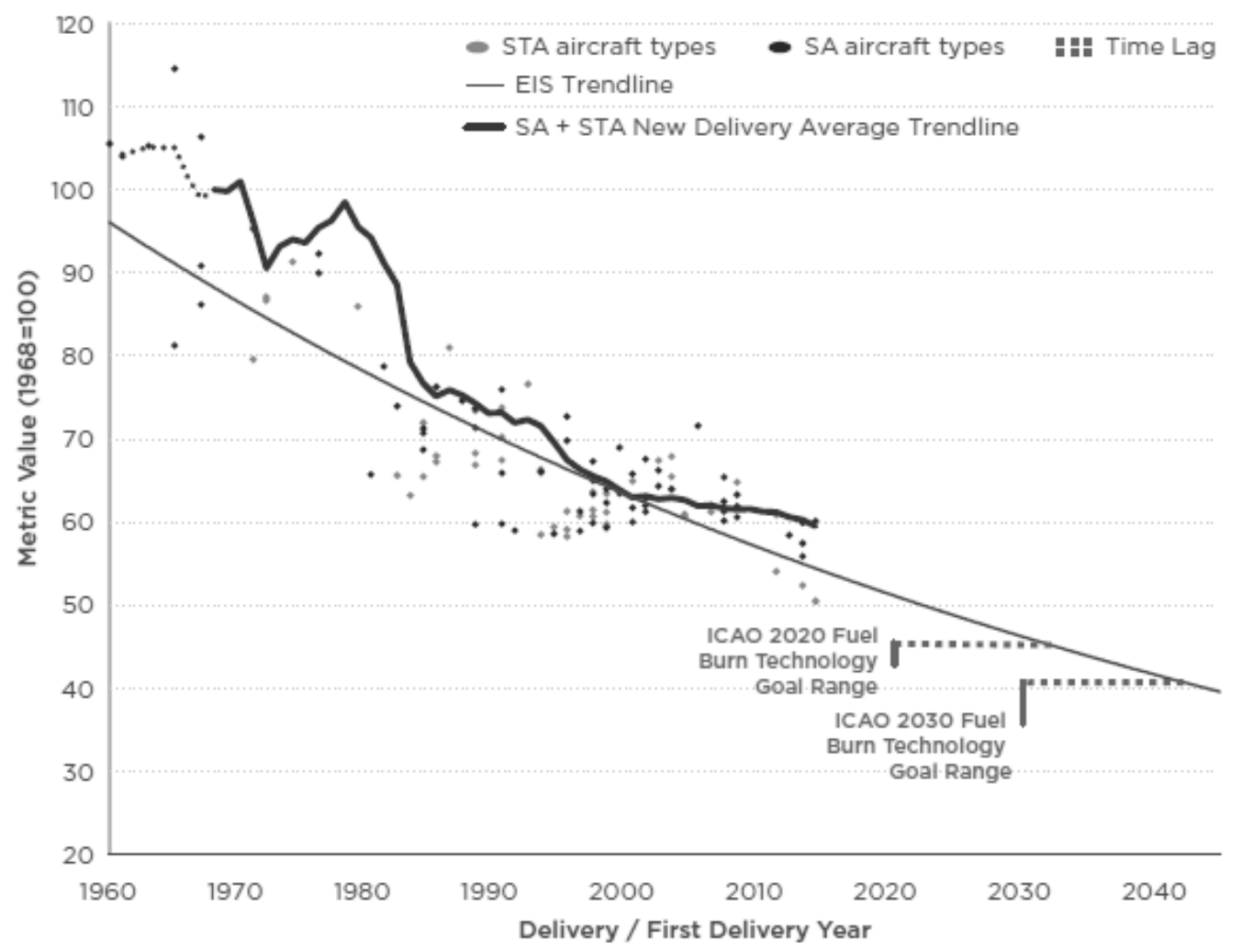

Figure 5 New single aisle and small twin-aisle jet aircraft metric value vs. ICAO fuel burn technology goals [5]

When analyzing figure 4 it is possible to conclude that fuel burn improvement slowed down noticeably after 1990. This trend has continued almost to 2010. During this time period no significant breakthroughs have taken place. After that the efficiency improvement pace has accelerated again and this trend is expected to continue. This has been caused by introduction of new aircraft models equipped with engines specifically designed from scratch to power them. Examples of such aircraft can be the Airbus A320Neo, Boeing 737Max, Boeing 787, Airbus A350. Introduction of Boeing 777X and Airbus A330Neo will continue to keep this tendency. According to ICAO estimates there is a potential for $40 \%$ improvement in fuel efficiency for single aisle and small twin-aisle aircraft in 2020 compared to 2000. Authors of the ICCT report have compared this value with fuel burn projection of new aircraft types under the ICAO metric value plotted by the year of entry into service and determined that there is a 12 years lag between the projected fuel burn improvement and the time needed to reach ICAO goals [5].

\section{CONCLUSION}

Because of high competition and dynamic changes in the markets airlines are forced to improve efficiency of their operations. As fuel costs can become as much as $43 \%$ of airline operating costs it is to be expected that large savings can be achieved by improving aircraft fuel efficiency. When analyzing historical data it can be noticed that aircraft fuel efficiency continually improves. The major breakthroughs occur when new widely produced type of aircraft or engine enters service. This has been proven in the period between years 1980 and 1990 when both Boeing 737 Classic and Airbus A320s were created. Another significant improvement can be observed after 2010 when the Boeing 787, Airbus A350, as well as A320Neo and Boeing 737Max entered service. As time progresses phasing out older aircraft will allow to keep the improving trend in aircraft fuel efficiency. In terms of meeting efficiency improvement standards set by ICAO calculations show that they are probably not 
going to be fulfilled. One of the reasons explaining this is that the technology does not develop quick enough. In addition to that many airlines cannot afford to modernize their fleets at sufficient speed. Last, but not least, improving fuel economy does not only bring financial benefits but also allows for reduced emissions and smaller ecological impact. As nowadays this topic is often discussed more and more airlines use this argument in their marketing campaigns promoting themselves as ecological and environmentally neutral.

\section{References}

[1] Peeters, P.M. - Middel, J. - Hoolhorst, A. Fuel efficiency of commercial aircraft. An overview of historical and future trends. Report of National Aerospace Laboratory NLR, November 2005, $3 \mathrm{p}$.

[2] Rumler, W. - Gunther, T. - Fricke, H. Flight Profile Variations due to the Spreading Practice of Cost Index Based Flight Planning. In: $4^{\text {th }}$ International Conference on Research in Air Transportation (ICRAT), Budapest, 2010

[3] Park, Y. - O'Kelly, M. E. Examination of cost-efficient aircraft fleets using empirical operation data in US aviation markets. Journal of Air Transport Management. 2018. Vol. 69. P. 224-234

[4] Edwards, H. - Dixon-Hardy, D. - Wadud, Z. Aircraft Cost Index and the Future of Carbon Emissions from Air Travel. Applied Energy. 2016. Vol. 164. P. 553-562.

[5] Kharina, A. - Rutherford, D. Fuel Efficiency trends for new commercial jet aircraft: 1960-2014. The International Council on Clean Transportation White Paper, August 2015

[6] European Aviation Environmental Report 2019, European Aviation Safety Agency, 2019, ISBN: 978-92-9210-214-2, 7-17 p.

[7] Norwegian Airlines Sustainability Report 2017. Norwegian Air Shuttle ASA, 2017. Available at: https://www.norwegian.com/globalasets/ip/documents/aboutus/company/environment/ norwegian-sustainability-report-2017.pdf

[8] Graver, B. - Rutherford, D. Transatlantic airline fuel efficiency ranking, 2017. The International Council on Clean Transportation White Paper, September 2018.

[9] On board a sustainable future. ICAO Environmental Report, 2016. Available at: https://www. icao.int/environmentalprotection/Documents/ICAO\%Environmental\%20Report\%202016.pdf

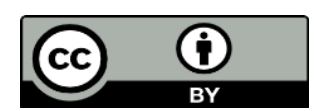

Article is licensed under a Creative Commons Attribution 4.0 International License 